\title{
Identification of a Protein from Rust Fungi Transferred from Haustoria into Infected Plant Cells
}

\author{
Eric Kemen, ${ }^{1}$ Ariane C. Kemen, ${ }^{1}$ Maryam Rafiqi, ${ }^{2}$ Uta Hempel, ${ }^{1}$ Kurt Mendgen, ${ }^{1}$ Matthias Hahn, ${ }^{2}$ \\ and Ralf T. Voegele ${ }^{1}$
}

${ }^{1}$ Phytopathologie, Fachbereich Biologie, Universität Konstanz, 78457 Konstanz, Germany; ${ }^{2}$ Phytopathologie, Fachbereich Biologie, Technische Universität Kaiserslautern, 67663 Kaiserslautern, Germany

Submitted 7 June 2005. Accepted 22 July 2005.

The formation of haustoria is one of the hallmarks of the interaction of obligate biotrophic fungi with their host plants. In addition to their role in nutrient uptake, it is hypothesized that haustoria are actively involved in establishing and maintaining the biotrophic relationship. We have identified a $24.3-\mathrm{kDa}$ protein that exhibited a very unusual allocation. Rust transferred protein 1 from Uromyces fabae (Uf-RTP1p) was not only detected in the host parasite interface, the extrahaustorial matrix, but also inside infected plant cells by immunofluorescence and electron microscopy. $U f$-RTP1p does not exhibit any similarity to sequences currently listed in the public databases. However, we identified a homolog of $\boldsymbol{U} f$-RTP1p in the related rust fungus Uromyces striatus (Us-RTP1p). The localization of $U f$-RTP1p and $U s$-RTP1p inside infected plant cells was confirmed, using four independently raised polyclonal antibodies. Depending on the developmental stage of haustoria, $U \boldsymbol{f}$-RTP1p was found in increasing amounts in host cells, including the host nucleus. Putative nuclear localization signals (NLS) were found in the predicted RTP1p sequences. However, functional efficiency could only be verified for the $U \boldsymbol{f}$-RTP1p NLS by means of green fluorescent protein fusions in transformed tobacco protoplasts. Western blot analysis indicated that $U f$-RTP1p and $U s$-RTP1p most likely enter the host cell as N-glycosylated proteins. However, the mechanism by which they cross the extrahaustorial membrane and accumulate in the host cytoplasm is unknown. The localization of RTP1p suggests that it might play an important role in the maintenance of the biotrophic interaction.

Additional keywords: haustorium, Medicago truncatula, protein secretion, Vicia faba.

Rust fungi (Basidiomycota; order Uredinales) represent a large group of plant pathogens causing disease on a variety of host plants, including several important crops, such as cereals,

E. Kemen and A. C. Kemen contributed equally to this work.

Corresonding author: R. T. Voegele; Telephone: +49 753188 4305; Fax: +49 753188 3035; E-mail: Ralf.Voegele@uni-konstanz.de

Nucleotide sequence data reported in this manuscript are available in the EMBL database under accession numbers AJ971316 (PIG15), AJ971426 (Uf-RTP1), and AJ971427 (Us-RTP1) legumes, and coffee (Brown and Hovmøller 2002; Deising et al. 2002). Together with the powdery mildew fungi (Ascomycota) and downy mildews (Oomycota), they form a class of pathogens classified as obligate biotrophs (Voegele and Mendgen 2003). Parasitic growth of these organisms is characterized by the formation of haustoria, specialized hyphae that invade individual host cells and establish a highly elaborate interface between host and parasite (Mendgen and Hahn 2002). Ever since their discovery more than 150 years ago (von Mohl 1853), the role of haustoria has been a matter of intensive debate. The construction of a haustorium-specific cDNA library by Hahn and Mendgen (1997) made it possible to analyze haustorial function at the molecular level. Since then, a number of genes preferentially or exclusively expressed in haustoria have been identified and their encoded products characterized. Haustoria of the rust fungus Uromyces fabae were subsequently shown to contain high concentrations of enzymes that are involved in the biosynthesis of vitamin B1 (Sohn et al. 2000) and polyols such as mannitol (Voegele et al. 2005). Furthermore, rust haustoria were recently shown to be responsible for the uptake of carbohydrates (Voegele et al. 2001). In addition, a large number of in planta-induced and haustorium-specific genes were identified to which no function could be assigned because of a lack of functional homologs in the databases (Jakupović et al. 2005). The products of these genes are candidates for being involved in a major potential function of haustoria that has been under debate for decades, setting up and maintaining compatibility with the host plant (Bushnell and Rowell 1981; Voegele and Mendgen 2003). Obligate biotrophic parasites are dependent on living host tissue for growth and reproduction. Therefore, they must have evolved mechanisms to circumvent or suppress surveillance systems linked to plant defense responses. Fungal suppressors for plant defense responses have been described, but they are either poorly characterized or nonproteinaceous (Basse et al. 1992; Knogge 1997; Moerschbacher et al. 1999). Nevertheless, it is likely that fungi, like their bacterial counterparts (Büttner and Bonas 2003), also deliver proteins as effectors to take control of host metabolism. These effectors modulate plant physiology in susceptible hosts, to sustain growth of the pathogen. In resistant hosts such effectors can be used by the plant to recognize a pathogen and to mount adequate defense responses. While there is indirect evidence that fungal proteins enter the host cell (Dodds et al. 2004), there is no direct proof for such a transfer, nor is there a mechanism known similar to the bacterial type III secretion system to translocate proteins into the host cell (Ghosh 2004). 
Since the narrow contact zone between host and parasite, the extrahaustorial matrix, represents the ideal trading place for nutrients and signals, we set out to analyze the localization of proteins with unknown function potentially secreted by haustoria. In the process of analyzing these proteins, we have identified a fungal protein that exhibits a stage-dependent distribution. In early stages of haustorial development, it is located in the extrahaustorial matrix, but as infection progresses, it is also detectable inside the infected host cell.

\section{RESULTS}

\section{Identification of a protein transferred}

from rust haustoria to infected host cells.

Differential hybridization of a haustorium-specific cDNA library from the broad bean rust $U$. fabae has previously revealed a number of in planta induced genes (PIGs), some of which appeared to be specifically expressed in haustoria (Hahn and Mendgen 1997). Sequencing of these PIGs revealed a number of open reading frames that encode potentially secreted proteins (M. Hahn, unpublished data). Identification of putative N-terminal leader peptides was based on results from an in silico analysis using programs SignalP V2.0 (Nielsen et al. 1997) and PSORTII (Nakai and Horton 1999). In order to study in detail the localization of these proteins in rust-infected leaf tissue, His-tagged fusion proteins were created to raise polyclonal antibodies. Antibodies were purified in a two-step procedure as described (Voegele et al. 2001), and their specificity was confirmed by Western blot analysis (data not shown). Antibodies were then used in immunofluorescence microscopy in order to localize the proteins in rust-infected leaf tissue. Among the candidate proteins analyzed this way, we identified a protein exhibiting a very unusual localization. Rust transferred protein 1 ( $U f$-RTP1p) was found not only in the haustorium-plant interface but also inside the infected host cell (Fig. 1A). Neighboring, noninfected plant cells exhibited no fluorescence. A closer examination revealed that $U f$-RTP1p was localized in the extrahaustorial matrix and in the cytoplasm and nucleus of the infected plant cell (Fig. 1A, insert).

Uf-RTP1 was originally identified as PIG7 by Hahn and Mendgen (1997). Like the majority of PIGs (22 out of 31), it exhibits no similarities to sequences deposited in the public databases. However, using a probe derived from $U f-R T P 1$, we identified a homolog of $U f-R T P 1$ in an expressed sequence tag (EST) library generated from Medicago truncatula leaves infected with the closely related rust fungus Uromyces striatus $(U s-R T P 1)$. Us-RTP1p showed a similar distribution to $U f$ RTP1p in the $U$. striatus-Medicago sativa pathosystem (Fig. 1B). It was also detected in the extrahaustorial matrix and inside infected plant cells. Neighboring, noninfected plant cells exhibited no fluorescence. A closer examination, however, revealed that $U s$-RTP1p was localized in the extrahaustorial matrix and in the cytoplasm, but in contrast to $U f$-RTP1p, it was barely visible in the nucleus of infected plant cells (Fig. 1B, insert).

Electron microscopy covering the interface of haustorium and host nucleus revealed gold particles mainly within the extrahaustorial matrix and in the region of the cytoplasm situated between extrahaustorial membrane and plant nucleus. Within the extrahaustorial matrix, gold particles accumulated close to the extrahaustorial membrane of both rust fungi, U. fabae (Fig. 2A) and $U$. striatus (Fig. 2B).

$U f$-RTP1p localization was initially determined using antibody S746p. In order to verify these data, three more antibodies were raised independently against different antigens (S844p, $U f$-HRTP1p; S805p, $U f$-RTP1Hp; S849p, Us-HRTP1p) and were used for Western blot analysis and immunofluorescence microscopy. All antigens comprised the sequence of the predicted mature RTP1p. While the initial antibody S746 was obtained in a guinea pig, all other antibodies were produced in rabbits. All purified antibodies showed very little background and cross-reacted with both proteins $U f$-RTP1p and $U s$ RTP1p. However, different signal strengths of the cross reactions with either $U f$-RTP1p or $U s$-RTP1p indicated the presence of different subpopulations within the four antibodies. The fact that they produced similar pictures confirmed the immunolocalization data originally obtained with antibody S746p (data not shown).

During these immunocytological analyses it became obvious that the localization of RTP1p changes as a function of haustorial maturation. In order to correlate these changes more precisely with haustorium development, light microscopical observations of living rust-infected mesophyll cells of freshly harvested Vicia faba leaves 1 to 12 days postinfection (dpi) were performed. These studies allowed us to discern three stages describing the expansion of the haustorial body and the behavior of the plant cytoplasm including the movement of the
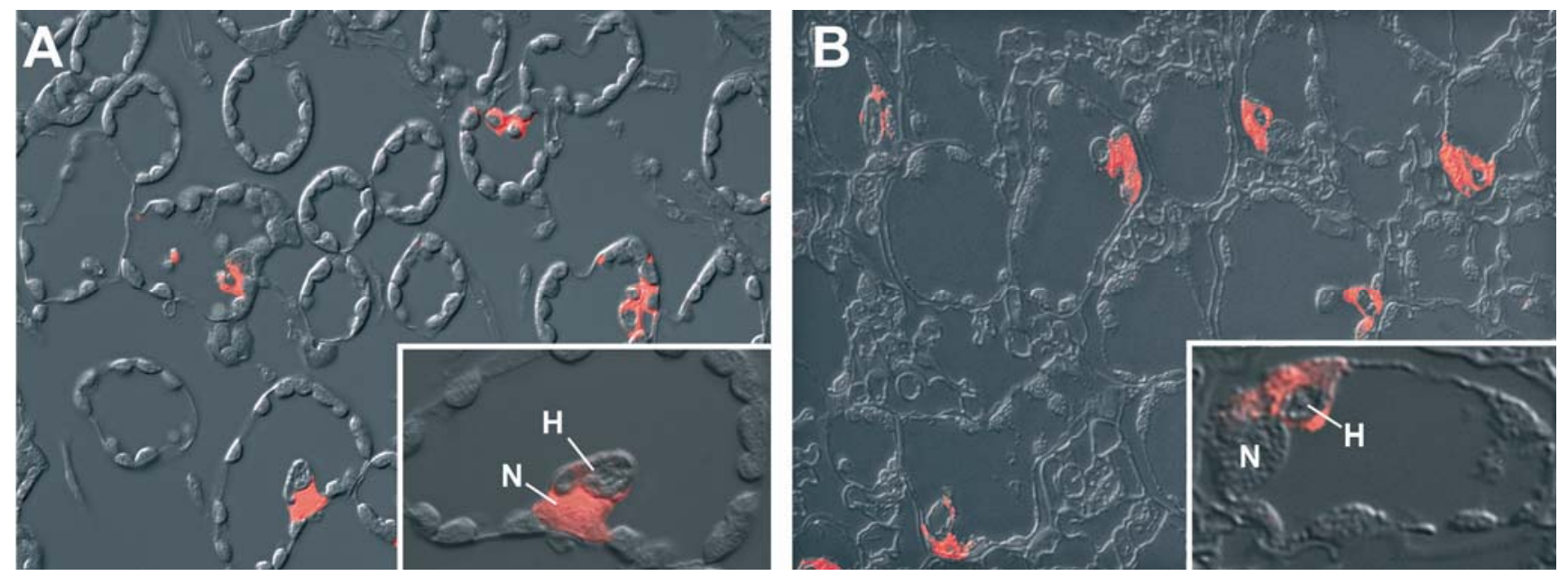

Fig. 1. Distribution of $U f$-RTP1p and $U s$-RTP1p in rust-infected leaf tissue. Immunolocalization of A, $U f$-RTP1p in Vicia faba and B, $U s$-RTP1p in $M e d i$ cago sativa. In infected cells, the areas around haustorial bodies are labeled. Neighboring noninfected cells do not show any labeling. In the nucleus closely associated to Uromyces fabae, haustoria exhibit fluorescence (insert in A). In nuclei adjacent to $U$. striatus haustoria, the fluorescence is hardly detectable (insert in B). Overlay of differential interference contrast and epifluorescence images using S844p (Uf-RTP1p) and S849p (Us-RTP1p), respectively, as primary antibody and Cy3 labeled goat anti-rabbit secondary antibody. $\mathrm{H}=$ haustorium, $\mathrm{N}=$ plant nucleus. 
nucleus and plastids (Fig. 3). Stage A is distinguished by small round haustoria. At the tip of the haustorial neck, a round haustorial body develops in the plant cytoplasm. At this stage, the fungus does not seem to disturb cytoplasmic streaming, as indicated by an even distribution of plastids. The nucleus is not in regular contact with the haustorium. Stage B is distinguished by haustoria with an elongated body. After polar extension of the haustorial body, the plant nucleus is in more or less close contact with the enlarged haustorium. Cytoplasmic streaming seems to be somewhat disturbed, since plastids tend to accumulate close to the nucleus-haustorium complex. Stage $C$ is distinguished by mature haustoria with lobes. The haustorial body produces lobes, and these appear to embrace the host nucleus. The nucleus remains closely attached to the haustorium. Cytoplasmic streaming appears to be impaired, since plastids cluster at the nucleus-haustorium complex. This leads to large areas in the cytoplasm with no chloroplasts.

This stage classification of haustorial development allowed us to establish a time-resolved pattern of $U f$-RTP1p distribution (Fig. 3). As long as streaming of the plant cell cytoplasm was not affected by the developing haustorium, a weak signal for $U f$-RTP1p was detected within the extrahaustorial matrix only (stage A). Later in this stage, the signal in the extrahaustorial matrix intensified strongly. When cytoplasmic streaming started to slow down around the nucleus-haustorium complex (stage B), Uf-RTP1p was observed for the first time within the host cell, in the area of the plant cytoplasm close to the haustorium. Especially, the contact zone between nucleus and haustorium exhibited bright fluorescence. At stage $C$, the plant nucleus exhibited prominent fluorescence in addition to the signals in the extrahaustorial matrix and the plant cytoplasm. However, the intensity of the signal was not evenly distributed within the nucleus but was strongest in the area facing the haustorium.

Other secreted proteins under investigation during this study were only detected in the extrahaustorial matrix. Pictures showing the localization of PIG15p are included to indicate the distribution typically seen for these proteins. PIG15p was detected in the extrahaustorial matrix throughout all three stages studied. In stage $\mathrm{C}$, the signal appeared less consistent and additional signals were detected within the haustorial body (Fig. 3).

\section{Characterization of $U f-R T P 1$ and $U s-R T P 1$.}

$U f-R T P 1$ contains an open reading frame of 660 nucleotides coding for a protein of 220 amino acids with a molecular mass of $24.3 \mathrm{kDa}$. Us-RTP1 contains a 684 nucleotide open reading frame coding for a protein of 228 amino acids with a molecular mass of $25.2 \mathrm{kDa}$. Both genes are interrupted by six introns situated at identical positions. Both genes are more than $64 \%$ identical, while the cDNAs share an identity of more than $73 \%$. Southern blot analysis of $U f-R T P 1$ indicated that the gene might be present in two copies (data not shown). EST sequencing of haustorium-specific cDNAs of $U$. fabae has revealed two variants of $U f-R T P l$ cDNAs differing in a single nucleotide position in the $3^{\prime}$ region (data not shown). However, allelic polymorphism cannot be ruled out at the moment, since the fungal stages analyzed are dikaryotic. Northern blot analysis confirmed the original classification of $U f-R T P l$ as an in planta induced gene (Fig. 4). We found strong hybridization signals in haustorial samples and much weaker signals in samples originating from infected leaves (which also contain haustoria). No other rust infection structures showed any $U f-R T P 1$ transcripts, indicating that the gene is haustorium-specifically expressed.

\section{Characterization of $\boldsymbol{U} \boldsymbol{f}$-RTP1p and $\boldsymbol{U} \boldsymbol{s}$-RTP1p.}

As pointed out already, $U f$-RTP1p and $U s$-RTP1p do not have any homologs in the public databases. Both proteins are characterized by relatively small molecular masses and are more than $71 \%$ identical (similarity $77 \%$ ). However, they are highly similar in their C-terminal portions (aa 90 to 220 for $U f$-RTP1p, identity $>91 \%$ ), whereas the $\mathrm{N}$-terminal portions are more divergent (identity < 44\%) (Fig. 5).

Various database searches for known protein patterns, profiles, and domains failed to reveal any indications for putative functions of both proteins. However, they revealed putative signals for protein secretion, nuclear localization, and N-glycosylation. Inspection of the N-termini with the SignalP V2.0 software (Nielsen et al. 1997) indicated 19- and 22-aa-long putative leader peptide sequences for $U f$-RTP1p and $U s$ RTP1p, respectively (Fig. 5). The mature polypeptides would therefore have molecular masses of 22.3 and $22.8 \mathrm{kDa}$, respectively. Heterologous expression of $U f-R T P 1$ and $U s-R T P 1$ in Pichia pastoris corroborated the functionality of the signal sequences, since RTP1p could be recovered from cell-free culture filtrates in both cases (data not shown).

In order to check whether the putative nuclear localization signals (NLS) in $U f$-RTP1p $\left(\mathrm{R}_{49} \mathrm{QHHKR}\left[\mathrm{X}_{9}\right] \mathrm{HRRHK}_{68}\right)$ and in $U s$-RTP1p $\left(\mathrm{R}_{59} \mathrm{LRKR}_{63}\right)$ are functional, various plasmid constructs expressing chalcone synthase-green fluorescent protein (CHS-GFP)-RTP1 fusion proteins under control of the
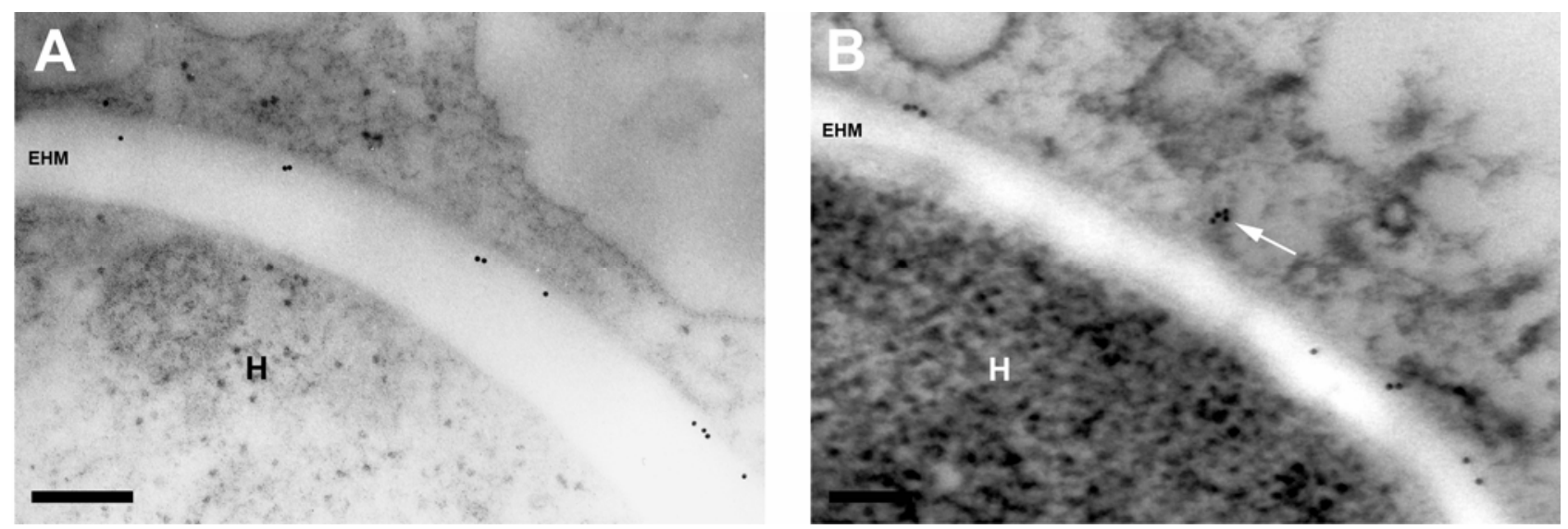

Fig. 2. Distribution of $U f$-RTP1p and $U s$-RTP1p at the plant haustorium interface. Electron microscopy of A, Uromyces fabae- and B, U. striatus-infected plant cells revealed signals in the extrahaustorial matrix (EHM) surrounding the haustorial body (H). Gold-labeling was most intense close to the extrahaustorial membrane. The typical signal within the plant cytoplasm (arrow) is demonstrated for $U$. striatus (B). Because of the poor preservation of membranes after the freeze-substitution needed for immunolocalization, membranes of potential vesicles in the cytoplasm were not visible. S844p (Uf-RTP1p) and S849p (Us-RTP1p) were used as primary antibody. Goat anti-rabbit secondary antibodies were labeled with $10 \mathrm{~nm}$ of gold $($ Bar $=200 \mathrm{~nm})$. 
cauliflower mosaic virus (CaMV) $35 \mathrm{~S}$ promoter were generated (Fig. 6A). Protoplasts derived from tobacco BY-2 suspension culture cells were transiently transformed with these plasmids, and the subcellular localization of GFP fluorescence was analyzed (Fig. 6B). A plasmid expressing a 72.3-kDa CHS-GFP fusion protein served as control. Cells transformed with CHSGFP showed fluorescence distributed over the cytoplasm and the nucleus. Although clearly exceeding the exclusion size of the nuclear pore complexes, a partial diffusion of CHS-GFP into the nucleus has been observed previously (Haasen et al. 1999). Unexpectedly, constructs expressing CHS-GFP-RTP1 chimeric proteins (full coding regions of $U f-R T P 1$ and $U s$ $R T P 1$ lacking their leader peptides) only rarely showed GFP fluorescence, even after repeated transformations. Other plasmids expressing $U f-R T P 1$ and $U s-R T P 1$ fused with their C-termini to CHS-GFP also result in GFP fluorescence of only few transformed tobacco cells (data not shown). We then used plasmids expressing CHS-GFP fusions with partial RTPl sequences, including the putative NLS regions for transformation. A fusion protein containing a 34-aa fragment including the putative
NLS of $U f$-RTP1p resulted in an exclusively nuclear fluorescence. The functionality of the proposed NLS sequence was confirmed by transformation of a construct expressing a mutagenized version of the $U f$-RTP1p NLS, in which three basic amino acids had been exchanged (H50D, K52Q, and R53L). Protoplasts transformed with this plasmid showed a diffuse fluorescence similar to that observed with CHS-GFP. We therefore conclude that the NLS of $U f$-RTP1p is functional. In contrast, a fusion protein containing a 29-aa fragment including the putative NLS of $U s$-RTP1p resulted in a diffuse fluorescence, similar to that of CHS-GFP. Our results, therefore, indicate the presence of a functional nuclear targeting signal for $U f-R T P l \mathrm{p}$ but do not support the presence of such a signal for $U s$-RTP1p.

Both proteins were also predicted to contain two potential $\mathrm{N}$-glycosylation sites. Interestingly, only one of these sites $\left(\mathrm{N}_{127}\right.$ for $U f$-RTP1p, $\mathrm{N}_{135}$ for $U s$-RTP1p) found in the conserved part of RTP1p occurs in both sequences. The second potential glycosylation site $\left(\mathrm{N}_{78}\right.$ for $U f$-RTP1p and $\mathrm{N}_{166}$ for $U s$ RTP1p) is not present in the other sequence.
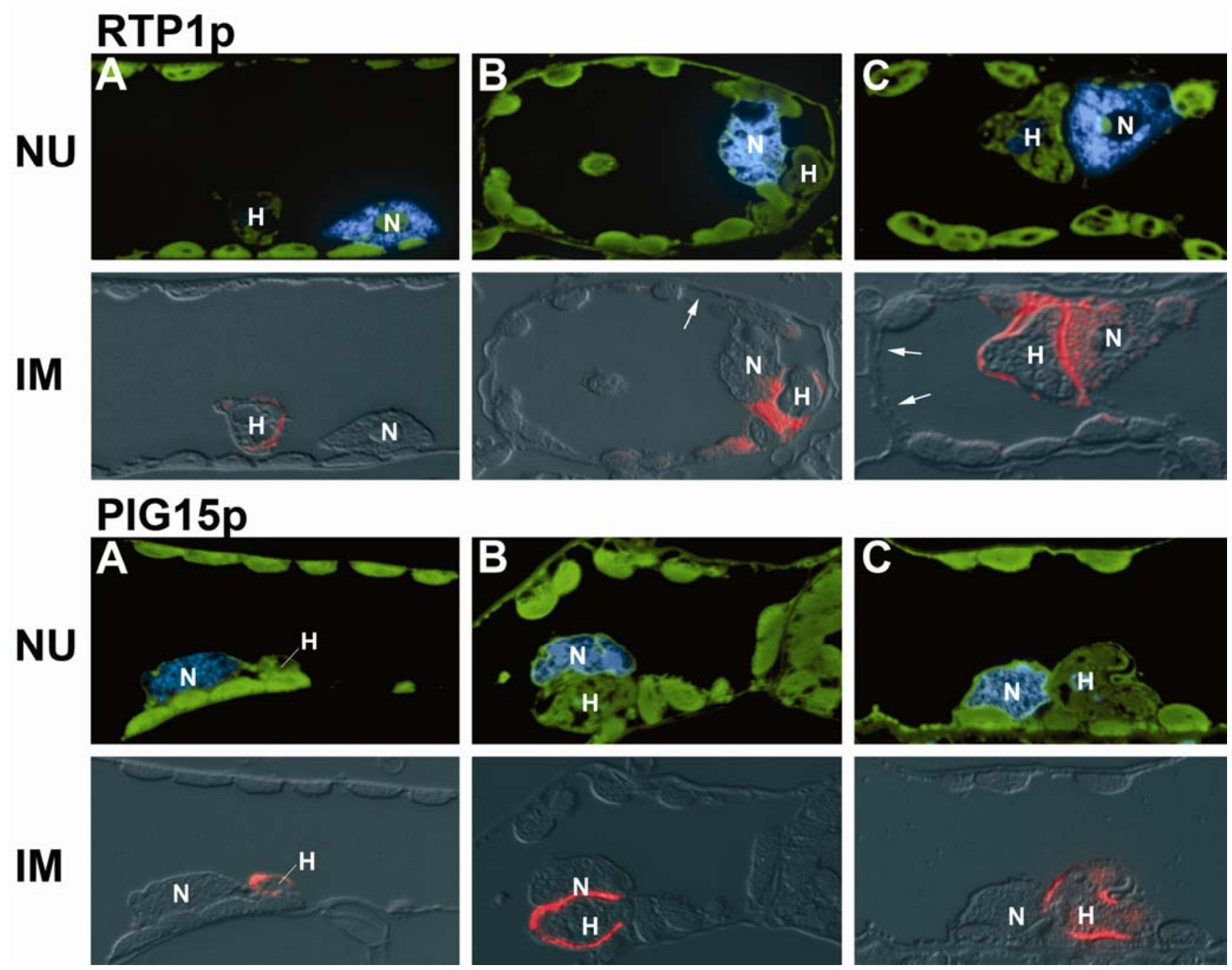

Fig. 3. Subcellular distribution of $U f$-RTP1p and PIG15p in different stages of haustorial development. $\boldsymbol{U} f$-RTP1p A, $U f$-RTP1p is restricted to the extrahaustorial matrix in early, small round haustoria of Uromyces fabae in Vicia faba. Uf-RTP1p is detected in the plant cytoplasm surrounding the haustorial body during the elongation stage. B, Irregular distribution of plastids (arrow) suggests disturbed cytoplasmic streaming. In late stages, when haustoria are lobed, the plant nucleus is closely attached to the haustorial contoures, plastids are unevenly distributed (arrows) and tend to accumulate in the vicinity of the haustorial complex. C, RTP1p is localized in the plant cytoplasm and in the plant nucleus. PIG15p A, In early stages of haustorial development, there is a weak signal in the extrahaustorial matrix. B, In later stages, the signal strongly increases, and $\mathbf{C}$, in late stages, the signal in the matrix starts to decrease but a weak signal occurs inside the haustorial body. NU, bisbenzimide nuclear stain and DIOC6(3) counter stain for cytoplasm and plastids. IM, Differential interference contrast and epifluorescence images using S750p (PIG15p) and S844p (Uf-RTP1p) as primary antibody and Cy3-labeled goat anti-rabbit secondary antibodies. $\mathrm{H}$ = haustorium, $\mathrm{N}=$ plant nucleus, arrows indicate chloroplast-free spaces. 


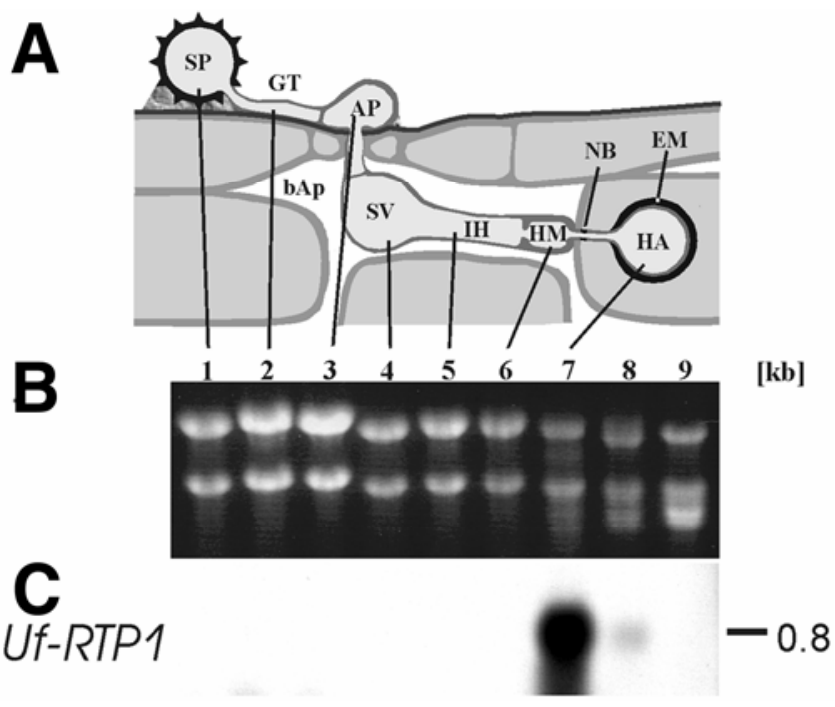

Fig. 4. Expression of $U f-R T P 1$ is haustorium specific. A, Schematic overview of rust-infection structures. B, Ethidium bromide-stained denaturing agarose gel (loading control). C, Northern blot. Lane 1, Uredospore (SP); lane 2, germ tube (GT); lanes 3 through 6 , in vitro infection structures harvested at the following stages (lane 3, appressorium [AP] stage [6 h]; lane 4 , substomatal vesicle [SV] stage $[12 \mathrm{~h}]$; lane 5 , infection hyphae $[\mathrm{IH}]$ stage [18 h]; lane 6, haustorial mother cell [HM] stage [21 h]); lane 7, isolated haustoria (HA); lane 8, infected leaves; lane 9, noninfected leaves. $\mathrm{bAp}=$ bulk apoplast, $\mathrm{NB}=$ neckband, $\mathrm{EM}=$ extrahaustorial matrix. Numbers on the right give size estimate in kilobases.
Western blot analysis of protein samples from infected leaf tissue or isolated haustoria always resulted in a doublet around $24 \mathrm{kDa}$ (Fig. 7). Treatment of the protein sample with endoglycosidase $\mathrm{H}_{\mathrm{f}}$ prior to analysis resulted in a single polypeptide that was smaller (around $23 \mathrm{kDa}$ ). This molecular mass corresponds well with the molecular weights predicted for the mature, secreted proteins. These results indicate that $U f$ RTP1p and $U s$-RTP1p are primarily found in their glycosylated forms in infected leaves.

\section{DISCUSSION}

In this publication, we report on the identification of a secreted protein, RTP1p, from two related rust fungi, which shows a stage-specific localization within infected host cells. The transfer of proteins to the host cell is now a well-established mechanism for bacterial pathogens of plants and animals (Alfano and Collmer 1996; Büttner and Bonas 2003; Cornelis and Wolf-Watz 1997). Bacterial effector proteins enter the host by direct injection via type III secretion systems (TTSS) (Ghosh 2004). Subsequently, they alter host metabolism, but the precise function of most bacterial effector proteins in plants is not yet known. Some were shown to act as proteases (Axtell et al. 2003), while others are targeted to the host nucleus and may act as transcription factors (Lahaye and Bonas 2001). In incompatible host-parasite interactions effectors may act as avirulence proteins that interact with their respective $R$-gene products and subsequently trigger the activation of plant defense mechanisms (Mudgett 2005).

$10 \quad 20 \quad 30 \quad 40 \quad 50$

M---SNLRLLFTIISLAAIARAQLVGSDVVLVRTSHQSMGKASVSYCR-----EMTRQHM :NLR:::TII LAA:ARA :.::VVLVRT H::MG ASVS CR ::.:.: MLFNPNLRVFLTIIILAAVARA--LTPGVVLVRTHHETMGLASVS ICRAEKDIHLGHPNV
10
20
30
40
50
60
70
80
90
100

--HKRELDQDANPGHRRHKSE PEGVKPSNHTSAPTPSSPPLTTVDLTPAKLNTACYPGTF :KR::D: AN. ::. K E E:.K SN. S :TPSSP:LTTVDLTPAKL:::CY GTF RLRKRDMDKFANTPQHS-KLELEDAKDSNYLSKATPSSPSLTTVDLTPAKLKSSCYLGTF
60
70
80
90
100
110
110
120
130
140
150
160

QAPLLEDCEVVIRAQLYNSTGSLQVSPGDYVFVSYGTCATVFQNPQYSKYSLQYNWAELG QAPLLEDCEVVIRAQLYNSTGSLQ.SPGDYVFVSYGTCATVFQNPQ S:Y: :QYNWAELG QAPLLEDCEVVIRAQLYNSTGSLQASPGDYVFVSYGTCATVFQNPQNSNYTIQYNWAELG 120 130 140

150 160

170
170
180
190
200
210
220

YVGGKLAGRCLLPEDHSMGGTAVFDTYLGRTYPDVI ISLQRFDDRDF I I PE Y: GGKLAGRCLLPEDHSMGGTAVFDTYLG: TYPDVI ISLQRFDDRDFI I PE YLGGKLAGRCLLPEDHSMGGTAVFDTYLGHTYPDVI ISLQRFDDRDF I IPE
180
190
200
210
220

Fig. 5. Alignment of $U f$-RTP1p and $U s$-RTP1p and sequence features of the two proteins. Pairwise alignment of the two RTP1p sequences ( $U f$-RTP1p top, $U s$-RTP1p bottom). Coding for the consensus sequence is: letter $=$ match, colon $=$ favorable mismatch, period $=$ neutral mismatch, and space $=$ unfavorable mismatch or gap. Predicted leader peptides are in bold lettering. Putative nuclear localization signals are in bold and italics. Potential N-glycosylation sites are bold and underlined. Tick marks indicate distances of 10 amino acids. 
The transfer of a fungal protein into the host cell constitutes a novel mechanism. Recently, Dodds and associates (2004) presented evidence that avirulence proteins from the rust fungus Melampsora lini are recognized inside the plant cell. These proteins are also likely to be synthesized and secreted specifically by the fungal haustorium and must be transported from the extracellular matrix across the host plasma membrane. Their interaction with cytoplasmic resistance gene products was demonstrated indirectly by Agrobacterium-mediated expression of the effector genes in plant cells expressing the corresponding resistance genes and by crossing transgenic lines of Linum usitatissimum expressing avirulence proteins with the resistant lines. However, although of similar size, AvrL567 and RTP1p do not share any homology. At present, only a few fungal effector proteins have been characterized. Of these, the best understood are the avirulence proteins from Cladospo-

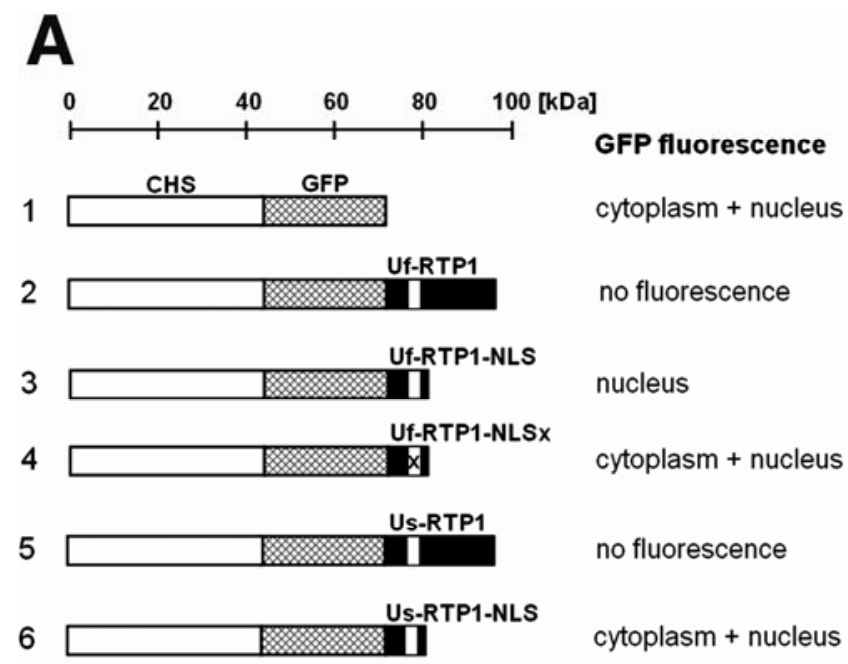

B
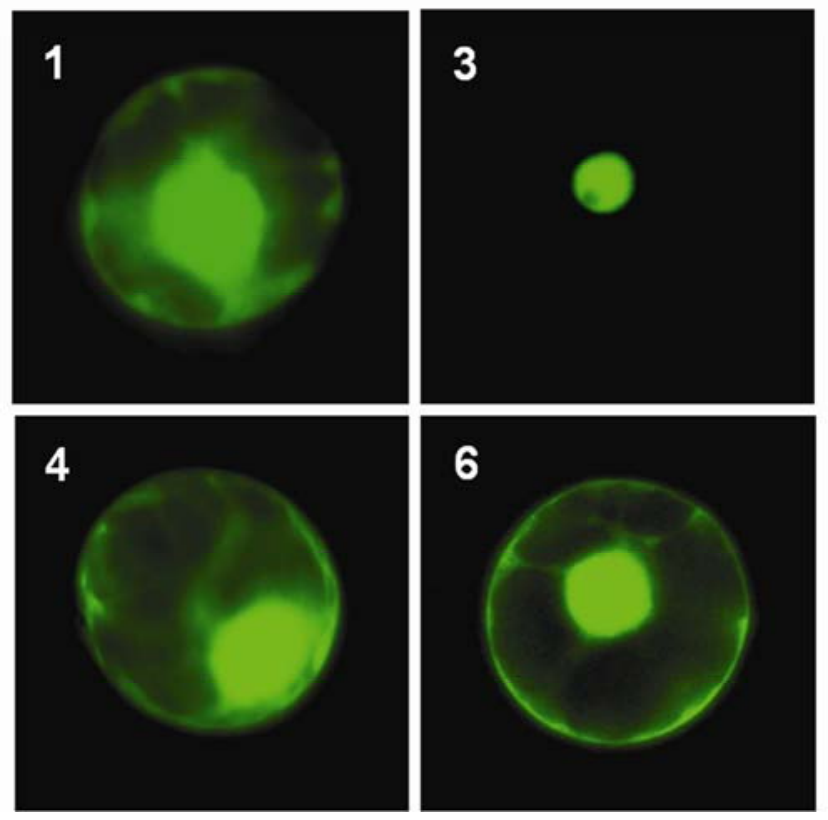

Fig. 6. Transient expression of GFP-RTPl fusion constructs in tobacco protoplasts. A, Schematic view of the fusion proteins tested for their subcellular localization. NLSx designates the mutagenized version of the $U f$ RTP1p nuclear localization signals (NLS), with amino acid exchanges H50D, K52Q, and R53L. CHS = chalcone synthase. B, Fluorescence micrographs showing tobacco protoplasts transformed with plasmid constructs encoding the fusion proteins depicted in A. rium fulvum, which are recognized on the plant cell surface (de Jong et al. 2002). The cellular localizations of other fungal effector proteins have not been well-characterized. However, most of the cloned $R$ genes indicate that recognition is likely in the plant cytoplasm rather than on the cell surface. In accordance with this, evidence for cytoplasmic recognition of an avirulence protein from Phytophthora infestans has been reported (Armstrong et al. 2005).

Our localization data for $U f$-RTP1p and $U s$-RTP1p are based on a direct detection of the proteins, using an immunocytological approach. One major point of criticism is the fact that we were only able to visualize $U f$-RTP1p within the plant cells using antibody methodology. However, work on obligate biotrophs is hampered by the lack of a functional stable transformation system and the nonculturability of these organisms in vitro (Voegele and Mendgen 2003). We have tried to address
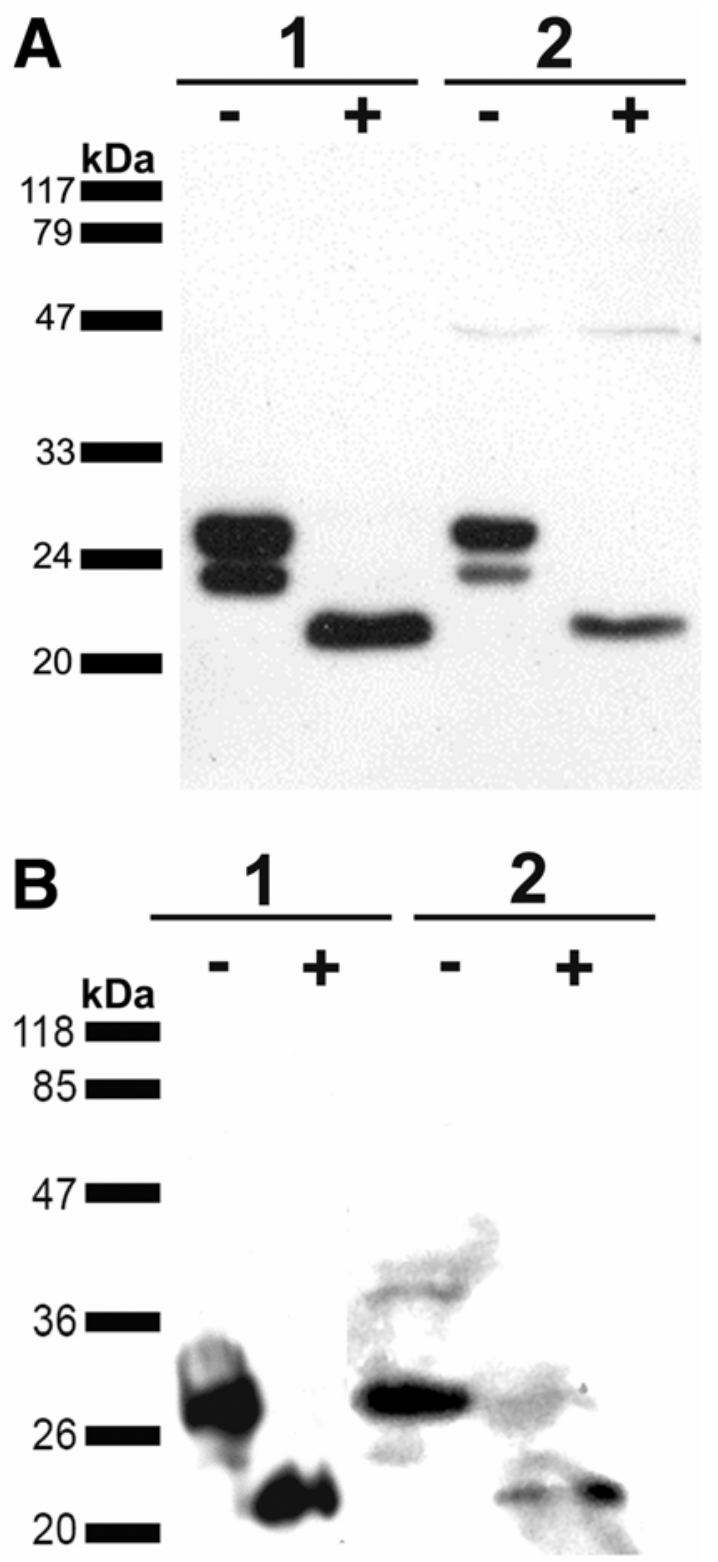

Fig. 7. Deglycosylation experiments for $U f$-RTP1p and $U s$-RTP1p. Detection of A, $U f$-RTP1p and $\mathbf{B}, U s$-RTP1p by immunoblot analysis. Block 1, Total protein of isolated haustoria. Block 2, Total protein of infected leaves. - indicates untreated samples, + indicates deglycosylated protein samples. Antibody dilutions (Uf-RTP1p, S746p and Us-RTP1p, S849p) were 1:10,000. Numbers on the left indicate molecular mass standards. 
this shortcoming by the use of two pathosystems ( $U$. fabae on $V$. faba and U. striatus on $M$. sativa) and four independently raised and purified antibodies. This approach should eliminate artifacts created by individual antigen responses of the antibody-producing organism (Schecklies 1996). Furthermore, we have established a double-purification protocol using positive and negative adsorption to eliminate artifacts caused by 'contaminating' antibodies, e.g., anti-His-tag antibodies. Another possible source for artifacts could be the cross reaction of an anti-peptide antibody with glycans as described by Charalambous and Feavers (2000). However, this possibility can also be ruled out, since pretreatment of the sections with protease completely erased the fluorescence signal (data not shown). The most convincing argument may be the fact that, among several other antibodies against $U$. fabae proteins that have been produced, purified, and tested in our laboratory by immunocytochemistry in rust-infected leaf tissue, none indicated a localization of its antigen comparable to the localization pattern of RTP1p (data for PIG15p and data not shown).

$U f-R T P 1$ was originally identified as PIG7 in a screen for PIGs by Hahn and Mendgen (1997). It belongs to a large set of genes (about two thirds of the initially described 31 PIGs) that do not have homologs in the public databases. This is not surprising, since genome sequencing projects have shown that up to $41 \%$ of the predicted proteins may not have homologous entries in the databases (Borkovich et al. 2004). However, it is reasonable to assume that, with a growing number of sequences from a variety of organisms, a lack of homology could be indicative of a special role for the corresponding gene product in this organism. It is also possible that a specific gene or gene product is restricted to a specific group of organisms, e.g., closely related pathogens with similar host species. This line of argument is supported by the identification of an Uf-RTPI homolog in the closely related rust fungus $U$. striatus (Us$R T P 1)$ but not in more distantly related species.

While the overall identity of $U f$-RTP1p and $U s$-RTP1p is around $71 \%$, it is more than $91 \%$ in the C-terminal part of the proteins (aa 90 to 220). The $\mathrm{N}$-terminal part of the two proteins, including the predicted signal sequence and the potential NLS, is considerably more divergent (similarity score $<44 \%$ ). This finding raises the speculation of a two-domain organization, with the $\mathrm{C}$-terminal domain possibly engaged with a conserved function and the N-terminal domain possibly adapted to the two different pathosystems. Alternatively, the two domains could take over different functions in the stage-dependent distribution we found.

A conspicuous feature of $U f$-RTP1p and, to a lesser extent, of $U s$-RTP1p is the localization within the host nucleus (Figs. 1 and 3 ). We were able to show the functionality of the $U f$ RTP1p NLS but not that of the $U s$-RTP1p NLS, using GFP fusion proteins. It is interesting to note that the potential nuclear localization signals are located in the less-conserved $\mathrm{N}$ terminal region of the two proteins. In contrast to $U f$-RTP1p, the $U s$-RTP1p NLS is hardly recognized by the prediction programs. Further work needs to be done on the localization of $U s$-RTP1p, and if convincing evidence can be obtained that it does get in to the nucleus, then further work on finding a NLS is warranted.

Up to now, it remains unclear how RTP1p crosses the extrahaustorial membrane and enters the host cell. As mentioned above, TTSS were only described so far for bacterial pathogens, and genome sequencing projects for fungi gave no indication for comparable translocation machinery. Possible alternative scenarios would be direct penetration of the extrahaustorial membrane or endocytosis coupled with a retrograde transport through Golgi apparatus and endoplasmic reticulum. The immunocytological localization of RTP1p gave no indica- tion for either mechanism because of the poor contrast of membranes after freeze substitution. This type of fixation was needed to retain antigenicity of the samples. Therefore, extensions of the extrahaustorial membrane into the host cell (Mims et al. 2001) or vesicles were not clearly visible, and hence, the allocation of gold particles to defined cell structures was not possible. However, without entering the cytoplasm, it would not be possible for a protein to enter the plant nucleus. It is interesting to note that haustorial samples and samples from infected leaves contained only glycosylated forms of RTP1p (Fig. 7). We therefore conclude that $U f$-RTP1p and $U s$-RTP1p enter the host cytoplasm as glycoproteins, a phenomenon that-to our knowledge-has not been described before in eukaryotic cells.

The two molecular-mass variants of RTP1p observed in haustorial and infected leaf samples are likely due to differences in N-glycosylation (Fig. 7). Removal of the sugar residues by endoglycosidase $\mathrm{H}_{\mathrm{f}}$ treatment shifts the two bands to a single band. This indicates that the protein backbone is identical in both isoforms and differences must be due to N-glycosylation. Modulations or variations in $\mathrm{N}$-glycosylation pattern have been described for a number of proteins. They can either be due to variable utilization of $\mathrm{N}$-glycosylation sites (Forno et al. 2004; Rudd et al. 2002) or alterations in the size of the glycosidic side chains (Tang et al. 2004). These modifications might be linked to alterations in localization, stability, or activity (Bellis 2004; Spiro 2004; Tang et al. 2004). The reason for the variation in $\mathrm{N}$-glycosylation of RTP1p remains to be determined. The similar ratios of the two bands in haustorial and infected leaf samples can be taken as evidence that they do not represent isoforms located in different compartments, i.e., extrahaustorial matrix or host cell.

Haustoria are the hallmark of the obligate biotrophic lifestyle, and it has been speculated that they not only serve in nutrient acquisition but also in setting up and maintaining this close interaction with the host plant. With $U f$-RTP1p and its homolog Us-RTP1p, we have two good candidates for gene products that might be involved in such a process. More work on these interesting proteins is needed to clarify their mode of transfer into the plant cell and their function. Currently, we are following various approaches, such as obtaining structural information about RTP1p and generating transgenic plants that express different variants of RTP1p.

\section{MATERIALS AND METHODS}

\section{Cultivation of plants and microorganisms.}

Cultivation of Vicia faba cv. con Amore, inoculation with uredospores, germination of spores, and growth of in vitrogrown infection structures were performed as described previously (Deising et al. 1991; Hahn and Mendgen 1997). Escherichia coli strains were grown in Luria-Bertani medium supplemented with the adequate concentration of antibiotic (Miller 1972). Cultivation of tobacco BY-2 suspension cultures and preparation of protoplasts was done as described (Merkle et al. 1996). Transient transformation of the protoplasts was performed according to the literature (Negrutiu et al. 1987).

\section{Nucleic acid manipulations.}

Isolation of RNA from infected leaves, infection structures, and isolated haustoria was performed as described by Hahn and Mendgen (1997). Us-RTP1 was isolated from a cDNA library from $U$. striatus-infected Medicago sativa leaves (7 dpi), which was constructed as described (Hahn and Mendgen 1997). For isolation of the Us-RTPl cDNA, a digoxigeninlabeled probe from $U f-R T P 1$ was used for plaque hybridization. Other nucleic acid manipulations were done using stan- 
dard techniques (Sambrook and Russel 2001). Sequencing was done using the Big-Dye terminator cycle sequencing ready reaction mix (PE Applied Biosystems, Foster City, CA, U.S.A.) on an ABI 377 HT automated sequencer (GATC, Konstanz, Germany). Sequencing data were assessed and analyzed using Chromas1.45 (Technelysium Pty. Ltd., Helensvale, Australia) and DNA-STAR (DNASTAR Inc., Madison, WI, U.S.A.). Nonradioactive hybridization was carried out according to Engler-Blum and associates (1993). Hybridizations were done using homologous probes at a hybridization temperature of $68^{\circ} \mathrm{C}$. Signal detection was performed using anti-digoxigenin AP Fab fragments, CSPD (Roche Diagnostics GmbH, Mannheim, Germany) as substrate, and autoradiography.

\section{Plasmid constructions.}

Plasmid pCHS-GFP (Haasen et al. 1999) carrying an expression cassette for a 72.3-kDa fusion protein between parsley chalcone synthase (CHS) and GFP, under control of the CaMV $35 \mathrm{~S}$ promoter, was provided by T. Merkle (Bielefeld, Germany). To create translational fusions with CHS-GFP and sequences of either Uf-RTPl or Us-RTP1, RTPl cDNAs were polymerase chain reaction (PCR)-amplified using primers extended with a BamHI and an EcoRI site, respectively. After restriction digest, fragments were inserted into pCHS-GFP so that inframe fusions with the $\mathrm{C}$ terminus of GFP were generated.

The following primers were used (restriction sites are underlined; numbers in parentheses indicate nucleotide position relative to the start of the coding region of $U f-R T P 1$ and $U s$ $R T P 1$ cDNAs, respectively). For amplification of $U f-R T P 1$, upper primer TGGAATTCC(58)AACTAGTAGGCTCAGATG TG(78) and lower primer GTGGATCCT(663)CATTCRGGTA TGATGAAATCC(642). For amplification of $U f$-RTP1-NLS, upper primer TGGAATTCAGTA(106)TGGGCAAAGCAAGT GTCAG(125) and lower primer GTGGATCCC(208) TGACTT GTGACGCCTGTGT(189). For amplification of Us-RTP1, upper primer TGGAATTCTCTC(73)CAGGGGTTGTTTTG $\mathrm{GT}(89)$ and lower primer same as for $U f-R T P 1$. For amplification of $U s-R T P 1$-NLS, upper primer identical to that for $U f$ $R T P 1$-NLS and lower primer TCGGATCCG(192)TCCCGCTT GCGAAGTCTGACA(171). $U f$-RTPI-NLSx cDNA was created by site directed mutagenesis of the putative bipartite NLS. The substitutions H50D, K52Q, and R53L were introduced by means of overlapping mutagenic PCR primers that introduced the following new codons into the $U f$-RTPl coding region:

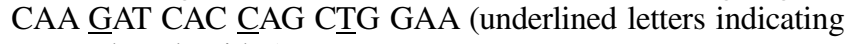
mutated nucleotides).

For the generation of antibodies the following constructs were made. The ' $\mathrm{H}$ ' in plasmid constructs and fusion proteins indicates the position of the introduced $6 \mathrm{x}$ His-tag. Plasmids pET28a::HPIG15, pET28a::HRTP1, and pET28a::Us-HRTP1 were constructed by introducing unique $N d e$ I and EcoRI restriction sites in PIG15, Uf-RTP1, and Us-RTPl by PCR. Plasmid pET28a::RTP1H was created by introducing unique $N c o$ I and $X h o I$ sites in $U f$-RTP1. PCR fragments of PIG15, Uf$R T P 1$, and $U s-R T P 1$ were cloned after digestion with the respective enzymes into vector pET28a(+) (Novagen, Madison, WI, U.S.A.), yielding His-tagged fusion proteins HPIG15p (22 to 280), $U f$-HRTP1p (20 to 220), $U f$-RTP1Hp (19 to 220), and $U s$-HRTP1p (23 to 228 ), respectively (numbers in brackets indicate the amino acids included in the fusion protein). All plasmid constructs were verified by sequencing.

\section{Expression of His-tagged fusion proteins,} antibody generation, and purification.

Overexpression of the fusion proteins was done using $E$. coli BL21(DE3) plysE (Novagen) and induction with isopropyl $\beta$ D-thiogalactopyranoside. Purification of the fusion protein was performed by using immobilized metal-ion affinity chromatography under denaturing conditions, according to the manufacturer's protocol (The QIAexpressionist; Qiagen, Hilden, Germany). Antibodies were obtained by repeated biweekly injections of rabbits with $500 \mu \mathrm{g}$ of purified fusion protein together with Freund's adjuvant (HPIG15p/S750, Uf-HRTP1p/S844, $U f$-RTP1Hp/S805, $U s$-HRTP1p/S849) or guinea pigs with 250 $\mu \mathrm{g}$ of purified fusion protein together with RAS adjuvant $(U f$ HRTP1p/S746). All sera were purified in a two-step procedure, according to Voegele and associates (2001). Antigens used for negative adsorption to remove undesired antibodies, including anti-His-tag antibodies, were $U f$-HRTP1p for S750, HPIG5p (His-tagged fusion protein of PIG5p [R. Voegele, unpublished results]) for S746, and HINVn (N-terminal part of $U$. fabae invertase INV1p, [R. Voegele, unpublished results]) for S844, S805, and S849. The flow-through was collected and applied to a column containing the fusion protein used for immunization. The adsorbed antigen-specific antibodies were eluted with $50 \mathrm{mM}$ glycine/ $\mathrm{HCl}, \mathrm{pH} 2.2$ and immediately neutralized.

\section{SDS-PAGE and immunoblot analyses.}

Proteins were separated on $12 \%$ sodium dodecyl sulfate-polyacrylamide gel electrophoresis (SDS-PAGE) gels (Laemmli 1970), and subsequent immunoblot analysis was performed as described by Sohn and associates (2000). As primary antibody, purified sera were used in dilutions of 1:10,000. Visualization was done using peroxidase-conjugated secondary antibodies (Sigma-Aldrich Chemie, Mannheim, Germany) and ECL Western blot detection reagent (GE Healthcare, Freiburg, Germany).

Proteins were isolated from rust-infected ( $8 \mathrm{dpi})$ and noninfected leaves by grinding in liquid nitrogen and subsequent transfer of the sample to extraction buffer $(125 \mathrm{mM}$ Tris/ $\mathrm{HCl}$, pH 6.8, 4\% SDS, $200 \mu \mathrm{M}$ phenylmethylsulfonyl fluoride, 100 $\mathrm{mM}$ dithiothreitol [DTT]) preheated to $60^{\circ} \mathrm{C}$. An incubation at $100^{\circ} \mathrm{C}$ for $10 \mathrm{~min}$ followed. After centrifugation, proteins were precipitated from the supernatant with acetone. The protein pellet was washed with ethanol, was resuspended in $1 \%$ extraction buffer, and was mixed with sample buffer. Haustorial protein composition was analyzed by resuspending isolated haustoria (Hahn and Mendgen 1992) directly in sample buffer. For deglycosylation studies, $30-\mu$ protein samples were treated with 3,000 units of endoglycosidase $\mathrm{H}_{\mathrm{f}}$ (New England Biolabs, Beverly, MA, U.S.A.) in $5 \mathrm{mM}$ sodium citrate, $\mathrm{pH}$ 5.5 , at $37^{\circ} \mathrm{C}$ for $3 \mathrm{~h}$.

Protein concentrations were determined by the Bradford method (Bradford 1976), using the BioRad protein assay dye (BioRad, Hercules, CA, U.S.A.), following the microassay procedure with dilutions of bovine serum albumin (BSA) as standard.

\section{Immunocytochemistry.}

For immunofluorescence microscopy, small pieces of rustinfected leaves were punched out 5 to $11 \mathrm{dpi}$, were fixed in a mixture of acetic acid and ethanol (1:3 vol/vol), and were washed in ethanol. Samples were then infiltrated with acrylic resin containing $80 \%$ (vol/vol) butyl-methacrylate, $20 \%$ (vol/vol) methyl-methacrylate, $40 \mathrm{mM}$ benzoyl-peroxide, and $10 \mathrm{mM}$ DTT. Polymerization took place at $0^{\circ} \mathrm{C}$ for $24 \mathrm{~h}$. The reaction was started by adding $0.15 \mathrm{mM} \mathrm{N}, \mathrm{N}$-dimethylaniline. Sections $(0.5 \mu \mathrm{m})$ were attached to slides coated with Biobond (BBI International, Cardiff, U.K.), etched by using acetone and blocked in Tris-buffered saline $(10 \mathrm{mM}$ Tris/HCl, $150 \mathrm{mM}$ $\mathrm{NaCl}, \mathrm{pH} 7.6[\mathrm{TBS}]$ ) containing 5\% (wt/vol) BSA and 5\% (vol/vol) goat serum (Serotec, Wiesbaden, Germany). After equilibration in blocking buffer $(0.1 \%$ BSA-C (wt/vol) in TBS), samples were incubated with polyclonal antibodies di- 
luted 1:100 in blocking buffer at room temperature for $2 \mathrm{~h}$. After six 5-min washes in equilibration buffer, an incubation followed, using a 1:250 dilution of goat anti-rabbit or goat anti-guinea pig conjugated with $\mathrm{Cy} 3$ (MoBiTech $\mathrm{GmbH}$, Göttingen, Germany) in equilibration buffer for $1 \mathrm{~h}$. Subsequently, sections were stained with $1 \mu \mathrm{M}$ DIOC6(3) (Kodak, Rochester, NY, U.S.A.) in TBS for $30 \mathrm{~s}$, in $0.001 \%$ (wt/vol) bisbenzimide in TBS for $10 \mathrm{~min}$ and were washed twice for $10 \mathrm{~min}$ in TBS.

For in vivo observations, freshly harvested leaves were infiltrated with MS medium (Murashige and Sköog 1962) supplemented with $1 \%$ sucrose and $2 \mathrm{mM}$ Tris/HCl, pH 7.6. Small pieces were cut out, and the epidermis was carefully lifted. The samples were mounted on slides in the infiltration medium and were examined at $19^{\circ} \mathrm{C}$.

Samples were visualized using an Axioplan2 imaging epifluorescence microscope (Zeiss, Oberkochen, Germany) equipped with an AxioCam HRm (filters: for $\mathrm{Cy} 3$, excitation filter $\mathrm{HQ}$ $545 / 30$, barrier filter HQ 610/75 and dichroic mirror Q 565 LP; for DIOC6(3), excitation filter HQ 480/40, barrier filter HQ 510 LP, and dichroic mirror Q 505 LP; for bisbenzimide, excitation filter D 360/50, barrier filter D 460/50, and dichroic mirror 400 DCLP).

For immunoelectron microscopy, rust-infected leaves were punched out $8 \mathrm{dpi}$ and were high-pressure frozen as described (Stark Urnau and Mendgen 1995). This was followed by freeze-substitution at $-80^{\circ} \mathrm{C}$ for $80 \mathrm{~h}$ in a substitution medium containing acetone/methanol ( $1: 1 \mathrm{vol} / \mathrm{vol}), 0.2 \%$ uranylacetate (wt/vol), $1 \%$ osmium tetroxide (wt/vol), and $2 \%$ glutaraldehyde. The samples were then gradually warmed to $-20^{\circ} \mathrm{C}$. After four 2 -h washes at $-20^{\circ} \mathrm{C}$ in acetone/methanol, samples were warmed to room temperature and were embedded in Epon-Araldite (Graham and Beveridge 1990) or Unicryl (BBI International, Cardiff, U.K.). Ultrathin serial sections were prepared and etched in $10 \% \mathrm{H}_{2} \mathrm{O}_{2}$, and free aldehyde groups were blocked in glycine buffer $(0.1 \mathrm{M}$ glycine in TBS). Immunostaining was performed as described for immunofluorescence microscopy. Primary antibodies were detected by $10 \mathrm{~nm}$ of gold-conjugated secondary antibody (Aurion, Wageningen, The Netherlands) (1:50 in TBS). Subsequently, the samples were stained according to Knauf and associates (1989). Observation and photographic film recording of images was performed with a Hitachi $\mathrm{H}-7000$ electron microscope at $50 \mathrm{kV}$.

\section{ACKNOWLEDGMENTS}

We are grateful to C. Giele, A. Schmid, and H. Vahlenkamp for expert technical assistance. This work was supported by a grant provided by the Deutsche Forschungsgemeinschaft to K. Mendgen and R. T. Voegele (Me 523/25-1) and MH (HA 1486/4-1).

\section{LITERATURE CITED}

Alfano, J. R., and Collmer, A. 1996. Bacterial pathogens in plants: Life up against the wall. Plant Cell 8:1683-1698.

Armstrong, M. R., Whisson, S. C., Pritchard, L., Bos, J. I., Venter, E., Avrova, A. O., Rehmany, A. P., Böhme, U., Brooks, K., Cherevach, I., Hamlin, N., White, B., Fraser, A., Lord, A., Quail, M. A., Churcher, C., Hall, N., Berriman, M., Huang, S., Kamoun, S., Beynon, J. L., Birch, P. R. 2005. An ancestral oomycete locus contains late blight avirulence gene Avr3a, encoding a protein that is recognized in the host cytoplasm. Proc. Natl. Acad. Sci. U. S. A. 102:7766-7771

Axtell, M. J., Chisholm, S. T., Dahlbeck, D., and Staskawicz, B. J. 2003. Genetic and molecular evidence that the Pseudomonas syringae type III effector protein AvrRpt2 is a cysteine protease. Mol. Microbiol. 49:1537-1546.

Basse, C. W., Bock, K., and Boller, T. 1992. Elicitors and suppressors of the defense response in tomato cells. Purification and characterization of glycopeptide elicitors and glycan suppressors generated by enzymatic cleavage of yeast invertase. J. Biol. Chem. 267:10258-10265.

Bellis, S. L. 2004. Variant glycosylation: an underappreciated regulatory mechanism for $\beta 1$ integrins. Biochim. Biophys. Acta 1663:52-60.

Borkovich, K. A., Alex, L. A., Yarden, O., Freitag, M., Turner, G. E., Read, N. D., Seiler, S., Bell-Pedersen, D., Paietta, J., Plesofsky, N., Plamann, M., Goodrich-Tanrikulu, M., Schulte, U., Mannhaupt, G., Nargang, F. E., Radford, A., Selitrennikoff, C., Galagan, J. E., Dunlap, J. C., Loros, J. J., Catcheside, D., Inoue, H., Aramayo, R., Polymenis, M., Selker, E. U., Sachs, M. S., Marzluf, G. A., Paulsen, I., Davis, R., Ebbole, D. J., Zelter, A., Kalkman, E. R., O’Rourke, R., Bowring, F., Yeadon, J., Ishii, C., Suzuki, K., Sakai, W., and Pratt, R. 2004. Lessons from the genome sequence of Neurospora crassa: Tracing the path from genomic blueprint to multicellular organism. Microbiol. Mol. Biol. Rev. 68:1-108.

Bradford, M. M. 1976. A rapid and sensitive method for the quantitation of microgram quantities of protein utilizing the principle of protein-dye binding. Anal. Biochem. 72:248-254.

Brown, J. K., and Hovmøller, M. S. 2002. Aerial dispersal of pathogens on the global and continental scales and its impact on plant disease. Science 297:537-541.

Bushnell, W. R., and Rowell, J. B. 1981. Suppressors of defense reactions: A model for roles in specificity. Phytopathology 71:1012-1014.

Büttner, D., and Bonas, U. 2003. Common infection strategies of plant and animal pathogenic bacteria. Curr. Opin. Plant Biol. 6:312-319.

Charalambous, B. M., and Feavers, I. M. 2000. Peptide mimics elicit antibody responses against the outer-membrane lipooligosaccharide of group B Neisseria meningitidis. FEMS (Fed. Eur. Microbiol. Soc.) Microbiol. Lett. 191:45-50.

Cornelis, G. R., and Wolf-Watz, H. 1997. The Yersinia Yop virulon: A bacterial system for subverting eukaryotic cells. Mol. Microbiol. 23:861867.

Deising, H., Jungblut, P. R., and Mendgen, K. 1991. Differentiationrelated proteins of the broad bean rust fungus Uromyces viciae-fabae, as revealed by high resolution two-dimensional polyacrylamide gel electrophoresis. Arch. Microbiol. 155:191-198.

Deising, H., Reimann, S., Peil, A., and Weber, W. E. 2002. Disease Management of Rusts and Powdery Mildews. Page 243-269 in: The Mycota XI: Agricultural Applications. F. Kempken, ed., Springer-Verlag, Berlin.

de Jong, C. F., Takken, F. L. W., Cai, X., de Wit, P. J. G M., and Joosten, M. H. A. J. 2002. Attenuation of Cf-mediated defense responses at elevated temperatures correlates with a decrease in elicitor-binding sites. Mol. Plant-Microbe Interact. 15:1040-1049.

Dodds, P. N., Lawrence, G. J., Catanzariti, A. M., Ayliffe, M. A., and Ellis, J. G. 2004. The Melampsora lini AvrL567 avirulence genes are expressed in haustoria and their products are recognized inside plant cells. Plant Cell 16:755-768.

Engler-Blum, G., Meier, M., Frank, J., and Müller, G. A. 1993. Reduction of background problems in nonradioactive Northern and Southern blot analyses enables higher sensitivity than ${ }^{32} \mathrm{P}$-based hybridizations. Anal. Biochem. 210:235-244.

Forno, G., Bollati Fogolin, M., Oggero, M., Kratje, R., Etcheverrigaray, M., Conradt, H. S., and Nimtz, M. 2004. N- and O-linked carbohydrates and glycosylation site occupancy in recombinant human granulocytemacrophage colony-stimulating factor secreted by a Chinese hamster ovary cell line. Eur. J. Biochem. 271:907-919.

Ghosh, P. 2004. Process of protein transport by the type III secretion system. Microbiol. Mol. Biol. Rev. 68:771-795.

Graham, L. L., and Beveridge, T. J. 1990. Evaluation of freeze-substitution and conventional embedding protocols for routine electron microscopic processing of eubacteria. J. Bacteriol. 172:2141-2149.

Haasen, D., Kohler, C., Neuhaus, G., and Merkle, T. 1999. Nuclear export of proteins in plants: AtXPO1 is the export receptor for leucine-rich nuclear export signals in Arabidopsis thaliana. Plant J. 20:695-705.

Hahn, M., and Mendgen, K. 1992. Isolation of ConA binding haustoria from different rust fungi and comparison of their surface qualities. Protoplasma 170:95-103.

Hahn, M., and Mendgen, K. 1997. Characterization of in planta-induced rust genes isolated from a haustorium-specific cDNA library. Mol. Plant-Microbe Interact. 10:427-437.

Jakupović, M., Heintz, M., Reichmann, P., Mendgen, K. and Hahn, M. 2005. Microarray analysis of expressed sequence tags from haustoria of the rust fungus Uromyces fabae. Fungal Genet. Biol., in press.

Knauf, G. M., Welter, K., Müller, M., and Mendgen, K. 1989. The haustorial host-parasite interface in rust-infected bean leaves after high-pressure freezing. Physiol. Mol. Plant Pathol. 34:519-530.

Knogge, W. 1997. Elicitors and suppressors of the resistance response. Page 159-182 in: Resistance of crop plants against fungi. H. Hartleb, R. Heitefuss, and H.-H. Hoppe, eds. Gustav Fischer, Jena, Stuttgart, Germany.

Laemmli, U. K. 1970. Cleavage of structural proteins during the assembly of the head of bacteriophage T4. Nature (London) 227:680-685.

Lahaye, T., and Bonas, U. 2001. Molecular secrets of bacterial type III effector proteins. Trends Plant Sci. 6:479-485. 
Mendgen, K., and Hahn, M. 2002. Plant infection and the establishment of fungal biotrophy. Trends Plant Sci. 7:352-356.

Merkle, T., Leclerc, D., Marshallsay, C., and Nagy, F. 1996. A plant in vitro system for the nuclear import of proteins. Plant J. 10:1177-1186.

Miller, J. H. 1972. Experiments in molecular genetics, Cold Spring Harbor Laboratory Press, Cold Spring Harbor, NY, U.S.A

Mims, C. W., Rodriguez Lother, C., and Richardson, E. A. 2001. Ultrastructure of the host-parasite interaction in leaves of Duchesnea indica infected by the rust fungus Frommeela mexicana var. indicae as revealed by high pressure freezing. Can. J. Bot. 79:49-57.

Moerschbacher, B. M., Mierau, M., Graessner, B., Noll, U., and Mort, A. J. 1999. Small oligomers of galacturonic acid are endogenous suppressors of disease resistance reactions in wheat leaves. J. Exp. Bot. 50:605-612.

Mudgett, M. B. 2005. New insights to the function of phytopathogenic bacterial type III effectors in plants. Annu. Rev. Plant. Biol. 56:509-531.

Murashige, T., and Sköog, F. 1962. A revised medium for rapid growth and bio-assay with tobacco tissue cultures. Physiol. Plantarum 15:473-497.

Nakai, K., and Horton, P. 1999. PSORT: A program for detecting sorting signals in proteins and predicting their subcellular localization. Trends Biochem. Sci. 24:34-35.

Negrutiu, I., Shillito, R., Potrykus, I., Biasini, G., and Sala, F. 1987. Hybrid genes in the analysis of transformation conditions. I. Setting up a simple method for direct gene transfer in plant protoplasts. Plant Mol. Biol. 8:363-373.

Nielsen, H., Engelbrecht, J., Brunak, S., and von Heijne, G. 1997. Identification of prokaryotic and eukaryotic signal peptides and prediction of their cleavage sites. Protein Eng. 10:1-6.

Rudd, P. M., Merry, A. H., Wormald, M. R., and Dwek, R. A. 2002. Glycosylation and prion protein. Curr. Opin. Struct. Biol. 12:578-586.

Sambrook, J., and Russel, D. W. 2001. Molecular cloning: A Laboratory Manual. Cold Spring Harbor Laboratory Press, Cold Spring Harbor, NY, U.S.A.
Schecklies, E. 1996. Polyklonale Antikörper: Eine Einführung in die Theorie und Praxis der Antikörperherstellung, VCH, Weinheim, Germany.

Sohn, J., Voegele, R. T., Mendgen, K., and Hahn, M. 2000. High level activation of vitamin B1 biosynthesis genes in haustoria of the rust fungus Uromyces fabae. Mol. Plant-Microbe Interact. 13:629-636.

Spiro, R. G. 2004. Role of N-linked polymannose oligosaccharides in targeting glycoproteins for endoplasmic reticulum-associated degradation. Cell Mol. Life Sci. 61:1025-1041.

Stark Urnau, M., and Mendgen, K. 1995. Sequential deposition of plant glycoproteins and polysaccharides at the host-parasite interface of Uromyces vignae and Vigna sinensis. Protoplasma 186:1-11.

Tang, W., Chang, S. B., and Hemler, M. E. 2004. Links between CD147 function, glycosylation, and caveolin-1. Mol. Biol. Cell 15:40434050.

Voegele, R. T., Hahn, M., Lohaus, G., Link, T., Heiser, I., and Mendgen, K. 2005. Possible roles for mannitol and mannitol dehydrogenase in the biotrophic plant pathogen Uromyces fabae. Plant Physiol. 137:190-198.

Voegele, R. T., and Mendgen, K. 2003. Rust haustoria: Nutrient uptake and beyond. New Phytol. 159:93-100.

Voegele, R. T., Struck, C., Hahn, M., and Mendgen, K. 2001. The role of haustoria in sugar supply during infection of broad bean by the rust fungus Uromyces fabae. Proc. Natl. Acad. Sci. U.S.A. 98:8133-8138.

von Mohl, H. 1853. Ueber die Traubenkrankheit. Botanische Zeitung $11: 585-590$.

\section{AUTHOR-RECOMMENDED INTERNET RESOURCES}

PSORTII: psort.ims.u-tokyo.ac.jp/form2.htm

SignalP V2.0: www.cbs.dtu.dk/services/SignalP-2.0/\#submission 